\title{
In ovo and Dietary Supplementation of Probiotics Affects Post-Hatch Expression of Immune-Related Genes in Broiler Chicks
}

\author{
Chasity M Pender ${ }^{1}$, Sungwon Kim ${ }^{1}$, Lindsay H Sumners ${ }^{1}$, Miranda M Ritzi ${ }^{1}$, Mark Young ${ }^{2}$ and Rami A Dalloul ${ }^{1 *}$ \\ ${ }^{1}$ Avian Immunobiology Laboratory, Department of Animal and Poultry Sciences, Virginia Tech, Blacksburg, VA 24061, USA \\ ${ }^{2}$ Star-Labs/Forage Research Inc., Clarksdale, MO, USA
}

*Corresponding author: Rami A Dalloul, Avian Immunobiology Laboratory, Department of Animal and Poultry Sciences, Virginia Tech, Litton-Reaves Hall \#3170, 175 West Campus Drive, Blacksburg, VA 24061, USA, Tel: 5402310633; Fax: 5402313010; E-mail: RDalloul@vt.edu

Received date: June 05, 2017; Accepted date: July 05, 2017; Published date: July 10, 2017

Copyright: ( 2017 Pender CM, et al. This is an open-access article distributed under the terms of the Creative Commons Attribution License, which permits unrestricted use, distribution, and reproduction in any medium, provided the original author and source are credited.

\begin{abstract}
During the first week post-hatch, the neonatal chick is immunologically vulnerable and subject to infectious threats found in the environment. Probiotics are live, non-pathogenic microorganisms known to have a positive effect on the host by improving the natural balance of gut microbiota and promoting animal health. The objective of this study was to determine the effects of administering probiotics in ovo and in the diet on broiler chick hatchability, and post-hatch immune organ weights and ileal immune-related gene expression. At embryonic day 18,1584 eggs were injected with nothing (Dry), $1 \times 10^{6}$, or $1 \times 10^{7}$ (P1 and P2 respectively) probiotic bacteria. The remaining 393 eggs were left non-injected to serve as a negative control. Immune organ weights and tissue samples were taken on DOH and $\mathrm{d} 4,6,8,14$, and 20 . No differences were observed for hatchability or relative bursa weights. Only on $\mathrm{d} 6$, the P2 birds receiving the probiotic-supplemented diet had larger spleens as a result of a 2-way interaction between in ovo treatment and post-hatch diet. Both in ovo and dietary administration of probiotics were able to modulate the expression of the immune-related genes in the ileum; however, expression patterns differed based on the gene, treatment, and time point evaluated. In conclusion, these results indicate that in ovo supplementation of this commercial probiotic product does not influence hatchability and is capable of differentially modulating expression of certain genes in the ileum. Furthermore, in ovo administration of probiotics has an effect similar to that of dietary supplementation endorsing its usage to potentially promote early colonization of beneficial bacteria to stimulate intestinal and immune system development.
\end{abstract}

Keywords: In ovo; Probiotic; Chickens; Immunity; Hatchability

\section{Introduction}

The immune system of the neonatal chick is immature and inefficient during the first week of life, rendering the bird extremely vulnerable to infectious threats found in the environment [1]. Immunomodulators are currently being studied and sought after to counteract the inadequacies of the chick immune system and promote host defense during this immunologically liable time. Furthermore, changes in the poultry industry, such as the banning of sub-therapeutic use of certain antimicrobials in early 2017, have created an impetus for finding alternatives capable of maintaining animal health without having negative consequences on performance and profit margins. Probiotics have received increasing attention as an alternative with their potential to stimulate the immune system and reduce the rate and severity of enteric infections in poultry [2-4]. There are several microbial species commonly utilized as probiotics including those of Lactobacillus, Bifidobacterium, Enterococcus, Bacillus, and Pediococcus [5,6]. Probiotic products may contain one or several different bacterial species.

The primary function of the gastrointestinal tract is to digest and absorb nutrients in order to meet metabolic demands for maintenance, normal growth, and development; additionally, it acts as a vital barrier preventing the entry of several potentially harmful pathogens $[7,8]$. The introduction of 'commensal' microbiota to the gastrointestinal tract is critical to the development of the gut-associated lymphoid tissues (GALT). Interactions between the microbiota, the host intestinal tract and its associated immune tissues are necessary for the complete and robust development of the gastrointestinal system [9]. The gut microbial profile can be manipulated with probiotics in order to create conditions favourable to enhancing growth and health. In poultry, probiotics can enhance performance [10], promote a healthy microbial balance, and enhance host defenses against several enteric pathogens through stimulation of the mucosal immune system $[11,12]$. Oral administration of probiotics results in enhanced heterophil oxidative burst and degranulation as well as augmented phagocytic capacity of macrophages $[1,13,14]$. Probiotics also influenced humoral and cell-mediated immune responses by increasing antibody production and upregulating $\mathrm{T}$ lymphocyte numbers and associated responses [15-17]. Probiotics have proven their ability to enhance the immune response by promoting the clearance of several economically important pathogens such as Eimeria spp., Salmonella spp., Escherichia coli and Clostridium perfringens, further asserting their potential use as an antibiotic alternative [6,18-20].

Traditionally, probiotics are administered in the feed or water supply to 1-day-old birds. However, as soon as the chick hatches and is exposed to the external environment, it quickly begins to establish the microbial community in the intestine [21]. In order to promote early establishment of beneficial strains, employing in ovo technology may be the solution. In ovo technology represents a means to take advantage of this crucial time and promote early colonization of beneficial bacteria in order to stimulate intestinal and immune system development [4]. Few researchers have entertained the idea of administering probiotics in ovo, which recently has been gaining more interest $[22,23]$. The earliest attempts of connecting these concepts 
demonstrated promising results where Salmonella typhimurium colonization was reduced in chicks administered an undefined cecal culture of bacteria in ovo [24]. Unfortunately, negative results in terms of hatchability, performance, and mortality have been noted, though these consequences may be attributed to the probiotic strain used and delivery site [22,24-26]. Edens et al. demonstrated positive results administering Lactobacillus reuteri in ovo in hatching chicks and turkey poults [27]. They found no differences among treatment groups when comparing the hatchability of embryos injected with $L$. reuteri in either the air cell or the amniotic fluid to non-inoculated controls. Similar results were also seen in turkey embryos. More recently, administration of a commercial (lactobacilli- and bifidobacteria-based) probiotic as early as day 18 embryonic age was shown not to impact hatchability and could enhance early performance [22] and reduce disease severity in broiler chickens challenged post-hatch [26]. The objective of this study was to determine the effects of administering a Lactobacillus-based probiotic (PrimaLac) in ovo and in the diet on broiler chick hatchability, post-hatch immune organ weights, and developmental expression of intestinal immune-related genes.

\section{Materials and Methods}

\section{Birds and treatments}

This study was approved and conducted under the guidelines of the Virginia Tech Institutional Animal Care and Use Committee. At embryonic day (d) 18, 1980 fertile Cobb 500 eggs were obtained from a commercial hatchery (Pilgrim's Pride, Broadway, VA) and transported to the Virginia Tech Turkey Research Center. Prior to injection, all eggs were candled to determine position of the air cell. Eggs were sanitized by swabbing the large end (outside of the air cell) with $0.5 \%$ sodium hypochlorite and once dried, they were sprayed with 70\% isopropyl alcohol. To create a guide and avoid cracking, a pilot hole was made in the center of the air cell of those eggs receiving injections using an 18gauge needle fitted with a rubber stopper to prevent the needle from piercing the air cell membrane. Needles were disinfected in between each injection by dipping in $0.5 \%$ sodium hypochlorite. Next, 1584 eggs were evenly divided and injected with either nothing (dry), or $1 \times$ $10^{6}$ or $1 \times 10^{7}$ (P1 and P2 respectively) probiotic bacteria dissolved in sterile water (PrimaLac W/S, Star-Labs Inc., containing Lactobacillus acidophilus, Lactobacillus casei, Enterococcus faecium, and Bifidobacterium bifidum). Injections were performed using a $1 \mathrm{~mL}$ syringe equipped with a 22 gauge $2.5 \mathrm{~cm}$ short bevel needle. A new syringe and needle were used for each injection. The remaining 396 eggs were not injected and served as a negative control. Eggs were placed into one of 6 replicate hatching trays (66 eggs/tray). On day of hatch $(\mathrm{DOH})$, birds were individually tagged, divided in half and placed into floor pens relative to treatment group. Half of the pens (6 pens/in ovo treatment) received supplemental probiotic (Primalac 454 FG, Star-Labs Inc.) in the feed at $1 \mathrm{~kg} /$ ton fed continuously throughout the trial. The basal diet consisted of a standard non-medicated broiler starter feed in crumble form provided from DOH to d19 and a standard non-medicated broiler grower feed in pellet form provided from d19 to d42. Feed and water were offered ad libitum throughout the study.

\section{Hatchability and post-hatch sample collection}

On $\mathrm{DOH}$, percent hatchability was recorded, and birds were weighed prior to placement and on sampling days. On $\mathrm{DOH}, \mathrm{d} 4,6,8$, 14, 20 and 42, six birds per treatment were randomly selected and euthanized by cervical dislocation. The bursa of Fabricius and spleen were excised and weighed, and relative organ weights were expressed as a percentage of live BW. The same six birds per treatment were sampled for gene expression analysis. The ileum, defined as the area posterior to the Meckel's diverticulum to the ileo-cecal junction, was sampled, rinsed in cold PBS, and placed in RNAlater (Qiagen, Germantown, MD) for subsequent gene expression analysis. The samples were stored at $-80^{\circ} \mathrm{C}$ until analysis.

\section{Ileal gene expression}

Intestinal samples were removed from $-80^{\circ} \mathrm{C}$ and a $20-30 \mathrm{mg}$ aliquot of each sample was weighed, placed into a $2 \mathrm{~mL}$ microcentrifuge tube along with a $5 \mathrm{~mm}$ stainless steel bead and $600 \mu \mathrm{L}$ lysis buffer, and homogenized using the TissueLyser II system (Qiagen) according to manufacturer's recommendation. Total RNA was extracted from individual intestinal tissues using the RNeasy mini kit following the animal tissue protocol (Qiagen). Following extraction, RNA was eluted by rinsing the column membrane twice with $25 \mu \mathrm{L}$ of RNase-free water. Total RNA concentration was determined at OD 260 (NanoDrop-1000, Thermo Fisher Scientific, Waltham, MA) and RNA purity was verified by evaluating the ratio of OD 260 to OD 280. Total RNA was diluted to $0.2 \mu \mathrm{g} / \mu \mathrm{L}$ in nuclease-free water. Reverse transcription was accomplished using the high capacity cDNA Reverse Transcription kit (Applied Biosystems, Carlsbad, CA) following the manufacturer's protocol, and the cDNA was stored at $-20^{\circ} \mathrm{C}$.

Quantitative real-time PCR (qRT-PCR) was performed using an ABI 7500 FAST Real-Time PCR System (Applied Biosystems) as described [26]. The cDNA was diluted 1:30 in nuclease-free water then $1 \mu \mathrm{L}$ of the diluted cDNA was added to each well of a 96-well plate. Next, $9 \mu \mathrm{L}$ of real-time PCR master mix containing $5 \mu \mathrm{L}$ FAST SYBR Green Master Mix (Applied Biosystems), $0.5 \mu \mathrm{L}$ each of $2 \mu \mathrm{M}$ forward and reverse primers and $3 \mu \mathrm{L}$ of sterile nuclease-free water per reaction were added to each well for a final volume of $10 \mu \mathrm{L}$. During the PCR reaction, samples were subjected to an initial denaturation phase of 20 sec at $95^{\circ} \mathrm{C}$ followed by 40 cycles of denaturation at $95^{\circ} \mathrm{C}$ for $3 \mathrm{sec}$ and annealing and extension at $60^{\circ} \mathrm{C}$ for $30 \mathrm{sec}$. Gene expression for interferon (IFN) $-\gamma$, interleukin (IL)-4, IL-13, inducible nitric oxide synthase (iNOS), lipopolysaccharide-induced tumor necrosis factor- $\alpha$ (LITAF), mucin (Muc)-2, trefoil family factor (TFF)-2, Toll-like receptor (TLR)-2 and TLR-4 was analyzed using glyceraldehyde-3phosphate dehydrogenase (GAPDH) as an endogenous control. Each reaction was run in duplicate. Primers were designed (Table 1) using the Primer Express 3.0 software (Applied Biosystems) and synthesized by MWG Operon (Huntsville, AL). Results from qRT-PCR were analyzed using the 7500 Real-Time PCR software (Applied Biosystems). Average gene expression relative to the $G A P D H$ endogenous control for each sample was calculated using the $2^{-\Delta \Delta C t}$ method [28]. The calibrator for each gene was the average $\Delta \mathrm{Ct}$ value from the negative control group for each sampling day.

\section{Statistical analysis}

Results were analyzed as a $4 \times 2$ factorial using the Fit Model platform in JMP 9.0 (SAS Institute Inc., Cary, NC). Percent hatchability was arc sine transformed prior to analysis. Differences in experimental treatments with individual birds as replicates within group were tested using Tukey-HSD following ANOVA. Values were considered statistically different at $\mathrm{P} \leq 0.05$. Results are reported as least squares means with standard errors. 
Citation: Pender CM, Kim S, Sumners LH, Ritzi MM, Young M, et al. (2017) In ovo and Dietary Supplementation of Probiotics Affects Post-Hatch Expression of Immune-Related Genes in Broiler Chicks. J Immuno Biol 2: 126. doi:10.4172/2476-1966.1000126

Page 3 of 8

\begin{tabular}{|c|c|c|}
\hline Target & Accession No & Nucleotide sequence $\left(5^{\prime} \rightarrow 3^{\prime}\right)$ \\
\hline GAPDH_F & \multirow{2}{*}{ NM_204305 } & CCTAGGATACACAGAGGACCAGGTT \\
\hline GAPDH_R & & GGTGGAGGAATGGCTGTCA \\
\hline IL-4_F & \multirow{2}{*}{ NM_001007079 } & GCTCTCAGTGCCGCTGATG \\
\hline IL-4_R & & GAAACCTCTCCCTGGATGTCAT \\
\hline IL-13_F & \multirow{2}{*}{ NM_001007085 } & CATGACCGACTGCAAGAAGGA \\
\hline IL-13_R & & CCGTGCAGGCTCTTCAGACT \\
\hline IFN-Y_F & \multirow{2}{*}{ NM_205149 } & GCTCCCGATGAACGACTTGA \\
\hline IFN-Y_R & & TGTAAGATGCTGAAGAGTTCATTCG \\
\hline iNOS_F & \multirow{2}{*}{ D85422 } & СCTGTACTGAAGGTGGCTATTGG \\
\hline iNOS_R & & AGGCCTGTGAGAGTGTGCAA \\
\hline LITAF_F & \multirow{2}{*}{ AY765397 } & TGTTCTATGACCGCCCAGTTC \\
\hline LITAF_R & & AGACGTGTCACGATCATCTGGTTA \\
\hline Muc-2_F & \multirow{2}{*}{ NM_001318434.1 } & TTCATGATGCCTGCTCTTGTG \\
\hline Muc-2_R & & СCTGAGCCTTGGTACATTCTTGT \\
\hline TFF-2_F & \multirow{2}{*}{ XM_416743.4 } & TGGTCCCCCAGGAATCTCA \\
\hline TFF-2_R & & CACCGACGCATTGAAGCA \\
\hline TLR-2_F & \multirow{2}{*}{ NM_204278 } & GCGAGCCCCCACGAA \\
\hline TLR-2_R & & GGAGTCGTTCTCACTGTAGGAGACA \\
\hline TLR-4_F & \multirow[t]{2}{*}{ NM_001030693 } & CCACACACCTGCCTACATGAA \\
\hline TLR-4_R & & GGATGGCAAGAGGACATATCAAA \\
\hline
\end{tabular}

Table 1: Primers used for relative real-time PCR (Primers designed by Primer Express software (Applied Biosystems, Foster City, CA)).

\section{Results}

\section{Hatchability and post-hatch immune organ weights}

No significant differences were observed for hatchability or BW during this study where hatchability ranged from $89 \%$ to $93 \%$. Neither in ovo delivery nor diet supplementation of the probiotic had an effect on bursa weights at any time point during the study (data not shown). On $\mathrm{d} 6$, in ovo treatment and diet resulted in a 2-way interaction on relative spleen weights with the $\mathrm{P} 2$ birds receiving the probioticsupplemented diet having a larger spleen $(0.093 \%)$ than all other groups except $\mathrm{P} 1$ birds given the control diet $(0.083 \%)(\mathrm{P}=0.02)$.

\section{Ileal gene expression}

On d14, in ovo treatment and diet resulted in a 2-way interaction on $T L R-2$ expression $(\mathrm{P}=0.048)$ (Table 2). Expression of TLR-2 was downregulated in $\mathrm{P} 1$ birds given the non-supplemented diet when compared to the birds receiving the dry punch and the same diet. When given probiotic supplementation in the diet, P1 birds displayed increased TLR-2 expression. There was a main effect of in ovo treatment $(\mathrm{P}=0.01)$ and diet $(\mathrm{P}<0.001)$ on $T L R-4$ expression on $\mathrm{d} 8$ (Table 3). TLR-4 levels were higher in $\mathrm{P} 2$ than the negative control and dry punch groups, while P1 had higher levels than the dry punch group. Additionally, chicks given the probiotic supplemented diet had augmented TLR-4 expression. On $\mathrm{d} 14$, in ovo treatment and diet presented a 2 -way interaction on $T L R-4$ gene expression $(\mathrm{P}=0.01)$. Upon examining the groups given the basal diet, P1 birds displayed downregulated expression of $T L R-4$ when compared to the dry punch group. In those groups given the probiotic supplemented diet, however, P1 birds demonstrated an increase in TLR-4 expression when compared to the dry punch and P2 groups. Dietary supplementation resulted in a decrease in TLR-4 expression in the dry punch and P2 birds.

\begin{tabular}{|c|c|c|c|c|c|c|}
\hline Age & DOH & d4 & d6 & d8 & d14 & d20 \\
\hline \multicolumn{7}{|l|}{ Main Effects } \\
\hline \multicolumn{7}{|l|}{ In Ovo Treatment } \\
\hline Neg & 1 & 1 & 1 & 1 & 1 & 1 \\
\hline Dry & 0.94 & 1.12 & 0.76 & 1.15 & 1.1 & 1.2 \\
\hline P1 & 1.29 & 1.06 & 1.28 & 1.26 & 1.07 & 1.73 \\
\hline P2 & 0.93 & 0.87 & 1.2 & 1.43 & 1.11 & 1.45 \\
\hline \multicolumn{7}{|l|}{ Dietary Treatment } \\
\hline Not Supplemented & -- & 1.00 & 1.00 & 1.00 & 1.00 & 1.00 \\
\hline Supplemented & -- & 0.91 & 0.93 & 1.28 & 0.98 & 0.91 \\
\hline \multicolumn{7}{|l|}{ Interactions } \\
\hline Neg/Not Supp & -- & 1.00 & 1.00 & 1.00 & $1.00^{\mathrm{ab}}$ & 1.00 \\
\hline Dry/Not Supp & -- & 0.98 & 0.62 & 1.40 & $1.21^{\mathrm{a}}$ & 1.27 \\
\hline P1/Not Supp & -- & 1.37 & 1.35 & 1.59 & $0.81^{b}$ & 2.12 \\
\hline P2/Not Supp & -- & 0.69 & 0.84 & 1.61 & $1.04^{\mathrm{ab}}$ & 1.08 \\
\hline Neg/Supp & -- & 0.86 & 0.72 & 1.68 & $0.87^{a b}$ & 0.90 \\
\hline Dry/Supp & -- & 1.11 & 0.67 & 1.60 & $0.86^{\mathrm{ab}}$ & 1.02 \\
\hline P1/Supp & -- & 0.71 & 0.88 & 1.68 & $1.22^{\mathrm{a}}$ & 1.27 \\
\hline P2/Supp & -- & 0.95 & 1.23 & 2.15 & $1.04^{\mathrm{ab}}$ & 1.75 \\
\hline \multicolumn{7}{|c|}{ Statistical Effects (P-Value) } \\
\hline In Ovo Treatment & 0.59 & 0.74 & 0.12 & 0.34 & 0.85 & 0.10 \\
\hline Dietary Treatment & -- & 0.60 & 0.67 & 0.08 & 0.85 & 0.57 \\
\hline In Ovo * Diet & -- & 0.20 & 0.28 & 0.66 & 0.048 & 0.17 \\
\hline
\end{tabular}

Table 2: Effect of in ovo and dietary probiotic supplementation on ileal $T L R-2$ gene expression (fold change). Different letters within a column indicate significant difference among treatment groups. ${ }^{1} \mathrm{Neg}=$ negative control; ${ }^{2}$ Dry $=$ dry punch; ${ }^{3} \mathrm{P} 1=1 \times 10^{6}$ probiotic bacteria; ${ }^{4} \mathrm{P} 2=1 \times 10^{7}$ probiotic bacteria; ${ }^{5} \mathrm{Not} \quad$ supp $=$ not supplemented; ${ }^{6}$ Supp $=$ supplemented.

On $\mathrm{d} 20$, there was a main effect of dietary treatment on iNOS gene expression where levels were decreased due to probiotic supplementation $(\mathrm{P}=0.04)$ (Table 4). Neither in ovo treatment nor diet altered TFF-2 expression during this study (data not shown). On d4, there was a main effect of diet on Muc-2 expression in the ileum where 
Citation: Pender CM, Kim S, Sumners LH, Ritzi MM, Young M, et al. (2017) In ovo and Dietary Supplementation of Probiotics Affects Post-Hatch

Page 4 of 8

levels of $M u c-2$ were elevated due to probiotic supplementation $(\mathrm{P}<0.0001)$ (Table 5). A similar pattern was observed on $\mathrm{d} 14(\mathrm{P}=0.003)$ and $\mathrm{d} 20(\mathrm{P}<0.0001)$. There was a main effect of in ovo treatment on Muc-2 expression on d6 where levels in $\mathrm{P} 1$ were significantly higher than the negative control and dry punch groups $(\mathrm{P}=0.01)$.

\begin{tabular}{|c|c|c|c|c|c|c|}
\hline Age & $\mathrm{DOH}$ & d4 & d6 & d8 & d14 & d20 \\
\hline \multicolumn{7}{|l|}{ Main Effects } \\
\hline \multicolumn{7}{|l|}{ In Ovo Treatment } \\
\hline Neg & 1.00 & 1.00 & 1.00 & $1.00^{\mathrm{bc}}$ & 1.00 & 1.00 \\
\hline Dry & 1.14 & 0.95 & 0.90 & $0.87^{\mathrm{c}}$ & 1.14 & 1.10 \\
\hline P1 & 1.38 & 1.15 & 1.11 & $1.29^{\mathrm{ab}}$ & 1.12 & 1.37 \\
\hline P2 & 1.09 & 0.86 & 1.30 & $1.59^{\mathrm{a}}$ & 0.85 & 1.48 \\
\hline \multicolumn{7}{|l|}{ Dietary Treatment } \\
\hline Not Supplemented & -- & 1.00 & 1.00 & $1.00^{\mathrm{b}}$ & $1.00^{\mathrm{a}}$ & 1.00 \\
\hline Supplemented & -- & 1.00 & 1.01 & $1.77^{\mathrm{a}}$ & $0.62^{b}$ & 0.95 \\
\hline \multicolumn{7}{|l|}{ Interactions } \\
\hline Neg/Not Supp & -- & 1.00 & 1.00 & 1.00 & $1.00^{\mathrm{abc}}$ & 1.00 \\
\hline Dry/Not Supp & -- & 0.83 & 0.67 & 1.21 & $1.39^{a}$ & 0.97 \\
\hline P1/Not Supp & -- & 1.34 & 1.12 & 1.27 & $0.90^{\mathrm{bcd}}$ & 1.18 \\
\hline P2/Not Supp & -- & 0.78 & 1.04 & 1.44 & $1.10^{\mathrm{ab}}$ & 1.14 \\
\hline Neg/Supp & -- & 0.97 & 0.78 & 1.98 & $0.69^{\mathrm{cd}}$ & 0.73 \\
\hline Dry/Supp & -- & 1.04 & 0.94 & 1.22 & $0.64^{\mathrm{de}}$ & 0.91 \\
\hline P1/Supp & -- & 0.96 & 0.87 & 2.59 & $0.97^{\mathrm{abc}}$ & 1.17 \\
\hline P2/Supp & -- & 0.91 & 1.28 & 3.46 & $0.46^{\mathrm{e}}$ & 1.40 \\
\hline \multicolumn{7}{|c|}{ Statistical Effects (P-Value) } \\
\hline In Ovo Treatment & 0.59 & 0.45 & 0.28 & 0.01 & 0.15 & 0.20 \\
\hline Dietary Treatment & -- & 0.98 & 0.94 & $\begin{array}{l}< \\
0.001\end{array}$ & $\begin{array}{l}< \\
0.001\end{array}$ & 0.75 \\
\hline In Ovo * Diet & -- & 0.42 & 0.33 & 0.080 & 0.01 & 0.66 \\
\hline
\end{tabular}

Table 3: Effect of in ovo and dietary probiotic supplementation on ileal $T L R-4$ gene expression (fold change). Different letters within a column indicate significant difference among treatment groups. ${ }^{1} \mathrm{Neg}=$ negative control; ${ }^{2}$ Dry $=$ dry punch; ${ }^{3} \mathrm{P} 1=1 \times 10^{6}$ probiotic bacteria; ${ }^{4} \mathrm{P} 2=1 \times 10^{7}$ probiotic bacteria; ${ }^{5} \mathrm{Not} \quad$ supp $=$ not supplemented; ${ }^{6}$ Supp $=$ supplemented.

Expression of $I F N-\gamma$ was downregulated on $\mathrm{d} 4$ due to dietary probiotic supplementation $(\mathrm{P}=0.0002)$ (Table 6). On $\mathrm{d} 14$, in ovo treatment and diet resulted in a 2-way interaction for $I F N-\gamma$ expression $(\mathrm{P}=0.0002)$. Within the groups receiving the basal diet, $\mathrm{P} 1$ and $\mathrm{P} 2$ exhibited a downregulation of IFN- $\gamma$ expression. In the groups receiving the supplemented diet, however, P1 displayed greater $I F N-\gamma$ expression than all other groups. Dietary supplementation of probiotics resulted in decreased IFN- $\gamma$ levels in the negative control and dry punch birds.

\begin{tabular}{|c|c|c|c|c|c|c|}
\hline Age & DOH & d4 & d6 & d8 & d14 & d20 \\
\hline \multicolumn{7}{|l|}{ Main Effects } \\
\hline \multicolumn{7}{|l|}{ In Ovo Treatment } \\
\hline Neg & 1.00 & 1.00 & 1.00 & 1.00 & 1.00 & 1.00 \\
\hline Dry & 0.85 & 1.04 & 0.86 & 1.00 & 0.96 & 1.00 \\
\hline P1 & 1.01 & 0.85 & 1.10 & 0.94 & 1.16 & 1.06 \\
\hline P2 & 0.83 & 0.75 & 0.90 & 1.25 & 0.90 & 1.07 \\
\hline \multicolumn{7}{|l|}{ Dietary Treatment } \\
\hline Not Supplemented & -- & 1.00 & 1.00 & 1.00 & 1.00 & $1.00^{\mathrm{a}}$ \\
\hline Supplemented & -- & 0.97 & 0.94 & 0.99 & 0.99 & $0.79^{b}$ \\
\hline \multicolumn{7}{|l|}{ Interactions } \\
\hline Neg/Not Supp & -- & 1.00 & 1.00 & 1.00 & 1.00 & 1.00 \\
\hline Dry/Not Supp & -- & 0.98 & 0.77 & 1.2 & 0.89 & 1.19 \\
\hline P1/Not Supp & -- & 0.76 & 1.39 & 1.09 & 0.93 & 0.99 \\
\hline P2/Not Supp & -- & 0.58 & 0.83 & 1.33 & 0.98 & 1.04 \\
\hline Neg/Supp & -- & 0.78 & 0.95 & 1.21 & 0.89 & 0.83 \\
\hline Dry/Supp & -- & 0.86 & 0.92 & 1.01 & 0.93 & 0.69 \\
\hline P1/Supp & -- & 0.75 & 0.83 & 0.98 & 1.29 & 0.94 \\
\hline P2/Supp & -- & 0.76 & 0.93 & 1.42 & 0.75 & 0.91 \\
\hline \multicolumn{7}{|c|}{ Statistical Effects (P-Value) } \\
\hline In Ovo Treatment & 0.33 & 0.32 & 0.54 & 0.31 & 0.38 & 0.96 \\
\hline Dietary Treatment & -- & 0.85 & 0.62 & 0.94 & 0.96 & 0.04 \\
\hline In Ovo * Diet & -- & 0.56 & 0.23 & 0.66 & 0.22 & 0.40 \\
\hline
\end{tabular}

Table 4: Effect of in ovo and dietary probiotic supplementation on ileal iNOS gene expression (fold change). Different letters within a column indicate significant difference among treatment groups. ${ }^{1} \mathrm{Neg}=$ negative control; ${ }^{2}$ Dry=dry punch; ${ }^{3} \mathrm{P} 1=1 \times 10^{6}$ probiotic bacteria; ${ }^{4} \mathrm{P} 2=1 \times 10^{7}$ probiotic bacteria; ${ }^{5} \mathrm{Not} \quad$ supp $=$ not supplemented; ${ }^{6}$ Supp=supplemented.

In ovo treatment and diet presented a 2-way interaction on LITAF expression on $\mathrm{d} 20(\mathrm{P}=0.02)$ (Table 7$)$. Expression of LITAF was significantly downregulated in $\mathrm{P} 2$ birds given the non-supplemented diet when compared to negative control and P1 birds given the same diet. No differences were noted among groups given the supplemented diets, but dietary supplementation did reduce LITAF levels in the negative control and P1 chicks.

There was a main effect of dietary treatment on $I L-4$ gene expression on $\mathrm{d} 4(\mathrm{P}=0.001)$ and $\mathrm{d} 20(\mathrm{P}=0.02)$ where $I L-4$ levels were decreased due to probiotic supplementation (Table 8). Neither in ovo treatment nor diet altered $I L-13$ expression during this study (data not shown).

\section{Discussion}

The aim of this study was to explore the effects of in ovo administration of the probiotic product PrimaLac W/S in broiler 
Citation: Pender CM, Kim S, Sumners LH, Ritzi MM, Young M, et al. (2017) In ovo and Dietary Supplementation of Probiotics Affects Post-Hatch

Page 5 of 8

chicks and evaluate those effects with and without dietary probiotic supplementation. In this experiment, in ovo supplementation of probiotics had no effect on hatchability further corroborating our previous findings $[22,26]$. Very few studies have been published regarding the concept of administrating probiotics via the in ovo route. Edens et al. compared the hatchability of broiler embryos injected with Lactobacillus reuteri in either the air cell or the amniotic fluid to noninoculated controls and found no differences among the treatment groups [27]. Similar results were also seen in turkey embryos [27]. Alternatively, other researchers have found that in ovo injection of some probiotic strains can negatively impact hatchability [24,25]. Our findings suggest that the probiotic bacteria in PrimaLac can be safely administered in ovo without negatively affecting hatchability.

\begin{tabular}{|c|c|c|c|c|c|c|}
\hline Age & $\mathrm{DOH}$ & d4 & d6 & d8 & d14 & d20 \\
\hline \multicolumn{7}{|l|}{ Main Effects } \\
\hline \multicolumn{7}{|l|}{ In Ovo Treatment } \\
\hline $\mathrm{Neg}$ & 1.00 & 1.00 & $1.00^{\mathrm{b}}$ & 1.00 & 1.00 & 1.00 \\
\hline Dry & 1.22 & 1.31 & $0.85^{b}$ & 0.98 & 1.06 & 1.09 \\
\hline P1 & 0.94 & 0.84 & $1.79^{\mathrm{a}}$ & 0.66 & 1.37 & 1.03 \\
\hline P2 & 1.65 & 1.15 & $1.22^{\mathrm{ab}}$ & 0.64 & 1.17 & 0.69 \\
\hline \multicolumn{7}{|l|}{ Dietary Treatment } \\
\hline Not Supplemented & -- & $1.00^{\mathrm{b}}$ & 1.00 & 1.00 & $1.00^{\mathrm{b}}$ & $1.00^{\mathrm{b}}$ \\
\hline Supplemented & -- & $2.05^{\mathrm{a}}$ & 1.22 & 1.08 & $1.42^{\mathrm{a}}$ & $1.92^{\mathrm{a}}$ \\
\hline \multicolumn{7}{|l|}{ Interactions } \\
\hline Neg/Not Supp & -- & 1.00 & 1.00 & 1.00 & 1.00 & 1.00 \\
\hline Dry/Not Supp & -- & 1.52 & 0.64 & 0.95 & 1.24 & 0.97 \\
\hline P1/Not Supp & -- & 0.95 & 1.45 & 0.85 & 1.68 & 0.98 \\
\hline P2/Not Supp & -- & 1.43 & 0.83 & 1.28 & 1.55 & 0.76 \\
\hline Neg/Supp & -- & 2.62 & 0.79 & 1.58 & 1.96 & 1.85 \\
\hline Dry/Supp & -- & 2.95 & 0.89 & 1.62 & 1.77 & 2.25 \\
\hline P1/Supp & -- & 1.94 & 1.74 & 1.13 & 2.20 & 2.00 \\
\hline P2/Supp & -- & 2.44 & 1.41 & 0.71 & 1.73 & 1.17 \\
\hline \multicolumn{7}{|c|}{ Statistical Effects (P-Value) } \\
\hline In Ovo Treatment & 0.1 & 0.18 & 0.01 & 0.45 & 0.22 & 0.12 \\
\hline Dietary Treatment & -- & $<0.0001$ & 0.19 & 0.29 & 0.003 & $<0.0001$ \\
\hline In Ovo * Diet & -- & 0.81 & 0.29 & 0.06 & 0.33 & 0.77 \\
\hline
\end{tabular}

Table 5: Effect of in ovo and dietary probiotic supplementation on ileal Muc-2 gene expression (fold change). Different letters within a column indicate significant difference among treatment groups. ${ }^{1} \mathrm{Neg}=$ negative control; ${ }^{2}$ Dry $=$ dry punch; ${ }^{3} \mathrm{P} 1=1 \times 10^{6}$ probiotic bacteria; ${ }^{4} \mathrm{P} 2=1 \times 10^{7}$ probiotic bacteria; ${ }^{5} \mathrm{Not} \quad$ supp $=$ not supplemented; ${ }^{6}$ Supp=supplemented.

The relative size of the bursa was not affected by in ovo or dietary supplementation of probiotics during this study. In ovo treatment and diet presented a 2-way interaction for relative spleen weight only on d6 with P2 birds given the supplemented diet having larger spleens than all other groups, except P1 birds given the control diet. Larger spleens have also been observed in studies where probiotics were added to the diets of broilers, suggesting that probiotics have an effect on the systemic immune system $[10,29,30]$. There are conflicting reports, however, suggesting that probiotics do not affect immune organ weights $[31,32]$.

\begin{tabular}{|c|c|c|c|c|c|c|}
\hline Age & $\mathrm{DOH}$ & d4 & d6 & d8 & d14 & d20 \\
\hline \multicolumn{7}{|l|}{ Main Effects } \\
\hline \multicolumn{7}{|l|}{ In Ovo Treatment } \\
\hline Neg & 1.00 & 1.00 & 1.00 & 1.00 & $1.00^{\mathrm{a}}$ & 1.00 \\
\hline Dry & 1.12 & 1.05 & 0.90 & 0.98 & $0.91^{a}$ & 0.83 \\
\hline P1 & 1.22 & 0.83 & 1.30 & 1.01 & $0.95^{\mathrm{a}}$ & 1.00 \\
\hline P2 & 1.01 & 0.91 & 1.37 & 1.21 & $0.62^{b}$ & 0.94 \\
\hline \multicolumn{7}{|l|}{ Dietary Treatment } \\
\hline Not Supplemented & -- & $1.00^{\mathrm{a}}$ & 1.00 & 1.00 & 1.00 & 1.00 \\
\hline Supplemented & -- & $0.55^{\mathrm{b}}$ & 1.26 & 0.94 & 0.86 & 1.07 \\
\hline \multicolumn{7}{|l|}{ Interactions } \\
\hline Neg/Not Supp & -- & 1.00 & 1.00 & 1.00 & $1.00^{\mathrm{a}}$ & 1.00 \\
\hline Dry/Not Supp & -- & 1.67 & 0.68 & 1.03 & $0.96^{a}$ & 0.88 \\
\hline P1/Not Supp & -- & 1.02 & 1.32 & 1.07 & $0.54^{b}$ & 1.25 \\
\hline P2/Not Supp & -- & 1.09 & 1.68 & 1.33 & $0.40^{\mathrm{b}}$ & 0.93 \\
\hline Neg/Supp & -- & 0.83 & 1.22 & 1.04 & $0.53^{b}$ & 1.34 \\
\hline Dry/Supp & -- & 0.55 & 1.46 & 0.98 & $0.45^{\mathrm{b}}$ & 1.04 \\
\hline P1/Supp & -- & 0.57 & 1.57 & 0.99 & $0.89^{a}$ & 0.91 \\
\hline P2/Supp & -- & 0.63 & 1.37 & 1.15 & $0.52^{\mathrm{b}}$ & 1.03 \\
\hline \multicolumn{7}{|c|}{ Statistical Effects (P-Value) } \\
\hline In Ovo Treatment & 0.58 & 0.66 & 0.20 & 0.79 & 0.01 & 0.61 \\
\hline Dietary Treatment & -- & 0.0002 & 0.15 & 0.72 & 0.18 & 0.60 \\
\hline In Ovo * Diet & -- & 0.19 & 0.22 & 0.98 & 0.0002 & 0.26 \\
\hline
\end{tabular}

Table 6: Effect of in ovo and dietary probiotic supplementation on ileal $I F N-\gamma$ gene expression (fold change). Different letters within a column indicate significant difference among treatment groups. ${ }^{1} \mathrm{Neg}=$ negative control; ${ }^{2}$ Dry $=$ dry punch; ${ }^{3} \mathrm{P} 1=1 \times 10^{6}$ probiotic bacteria; ${ }^{4} \mathrm{P} 2=1 \times 10^{7}$ probiotic bacteria ${ }^{5}$ Not supp=not supplemented; ${ }^{6}$ Supp=supplemented.

In spite of the considerable amount of published data regarding the efficacy of probiotics in poultry, the exact mechanism of how probiotics alter the immune system is still not fully understood. Our goal was to identify patterns of gene expression underlying the effects of probiotic supplementation on the immune system, particularly at the gut level. To observe the effects of probiotics on innate immunity, we evaluated the expression of TLR-2, TLR-4, iNOS, Muc-2 and TFF-2 in the ileum. The TLR family is a highly conserved group of proteins that act as pathogen recognition receptors (PRR), recognizing microbe-associated molecular patterns (MAMPs) that are expressed 
Citation: Pender CM, Kim S, Sumners LH, Ritzi MM, Young M, et al. (2017) In ovo and Dietary Supplementation of Probiotics Affects Post-Hatch

Page 6 of 8

on infectious agents. They play a fundamental role in pathogen detection and are responsible for the initiation and regulation of the innate response.

\begin{tabular}{|c|c|c|c|c|c|c|}
\hline Age & DOH & d4 & d6 & d8 & d14 & d20 \\
\hline \multicolumn{7}{|l|}{ Main Effects } \\
\hline \multicolumn{7}{|l|}{ In Ovo Treatment } \\
\hline Neg & 1.00 & 1.00 & 1.00 & 1.00 & 1.00 & 1.00 \\
\hline Dry & 0.88 & 0.91 & 0.94 & 0.97 & 1.10 & 1.04 \\
\hline $\mathrm{P} 1$ & 0.97 & 1.06 & 1.00 & 0.91 & 1.11 & 1.00 \\
\hline P2 & 1.04 & 0.98 & 0.88 & 0.9 & 1.11 & 0.90 \\
\hline \multicolumn{7}{|l|}{ Dietary Treatment } \\
\hline Not Supplemented & -- & 1.00 & 1.00 & 1.00 & 1.00 & $1.00^{\mathrm{a}}$ \\
\hline Supplemented & -- & 0.90 & 0.95 & 1.08 & 0.89 & $0.80^{\mathrm{b}}$ \\
\hline \multicolumn{7}{|l|}{ Interactions } \\
\hline Neg/Not Supp & -- & 1.00 & 1.00 & 1.00 & 1.00 & $1.00^{\mathrm{a}}$ \\
\hline Dry/Not Supp & -- & 0.80 & 1.05 & 1.07 & 1.08 & $0.83^{\mathrm{abc}}$ \\
\hline $\mathrm{P} 1 /$ Not Supp & -- & 1.11 & 1.08 & 0.90 & 1.14 & $0.89^{\mathrm{ab}}$ \\
\hline P2/Not Supp & -- & 0.87 & 1.02 & 0.91 & 1.04 & $0.66^{c d}$ \\
\hline Neg/Supp & -- & 0.81 & 1.13 & 1.00 & 0.87 & $0.58^{\mathrm{d}}$ \\
\hline Dry/Supp & -- & 0.85 & 0.94 & 1.14 & 0.98 & $\begin{array}{l}0.75^{a b c} \\
d\end{array}$ \\
\hline $\mathrm{P} 1 /$ Supp & -- & 0.83 & 1.04 & 1.04 & 0.93 & $0.65^{\mathrm{cd}}$ \\
\hline P2/Supp & -- & 0.89 & 0.86 & 1.02 & 1.03 & $0.72^{\mathrm{bcd}}$ \\
\hline \multicolumn{7}{|c|}{ Statistical Effects (P-Value) } \\
\hline In Ovo Treatment & 0.78 & 0.55 & 0.60 & 0.73 & 0.66 & 0.56 \\
\hline Dietary Treatment & -- & 0.15 & 0.53 & 0.29 & 0.11 & 0.001 \\
\hline In Ovo * Diet & -- & 0.30 & 0.55 & 0.7 & 0.79 & 0.020 \\
\hline
\end{tabular}

Table 7: Effect of in ovo and dietary probiotic supplementation on ileal LITAF gene expression (fold change). Different letters within a column indicate significant difference among treatment groups. ${ }^{1} \mathrm{Neg}=$ negative control; ${ }^{2}$ Dry $=$ dry punch; ${ }^{3} \mathrm{P} 1=1 \times 10^{6}$ probiotic bacteria; ${ }^{4} \mathrm{P} 2=1 \times 10^{7}$ probiotic bacteria; ${ }^{5} \mathrm{Not} \quad$ supp=not supplemented; ${ }^{6}$ Supp=supplemented.

Though it is evident that probiotic supplementation resulted in differential expression patterns of TLRs, and thus the innate immune system, it cannot be conclusively determined how probiotics influence localized innate responses under healthy conditions. As such, the presence of an enteric challenge might shed some light on the mechanistic functions of probiotic bacteria, and help us determine their impact on TLR pathways consistent with appropriate responses to those challenges. To this end, we reported reduced disease severity in birds inoculated with this probiotic at embryonic day 18 followed by a coccidia challenge post-hatch [26].
When exposed to antigens or chemotactic agents, macrophages will begin to produce $i N O S$. This enzyme leads to the production of nitric oxide, which will subsequently react with superoxide anions to generate toxic derivatives, allowing macrophages to proficiently kill numerous types of pathogens [33]. Though no effects were observed in the in ovo treatment groups, dietary administration of probiotics resulted in a downregulation of iNOS gene expression on $\mathrm{d} 20$, suggesting PrimaLac may possess an anti-inflammatory function. The Muc-2 gene is responsible for encoding mucin production, which is mediated by $\mathrm{T}$ lymphocytes and Th2 cytokines [34].

\begin{tabular}{|c|c|c|c|c|c|c|}
\hline Age & DOH & d4 & d6 & d8 & d14 & d20 \\
\hline \multicolumn{7}{|l|}{ Main Effects } \\
\hline \multicolumn{7}{|l|}{ In Ovo Treatment } \\
\hline Neg & 1.00 & 1.00 & 1.00 & 1.00 & 1.00 & 1.00 \\
\hline Dry & 1.17 & 1.18 & 0.96 & 0.93 & 1.26 & 1.11 \\
\hline P1 & 1.12 & 0.82 & 1.36 & 1.12 & 1.20 & 1.02 \\
\hline P2 & 1.33 & 0.75 & 1.04 & 1.02 & 1.13 & 1.35 \\
\hline \multicolumn{7}{|l|}{ Dietary Treatment } \\
\hline Not Supplemented & -- & $1.00^{\mathrm{a}}$ & 1.00 & 1.00 & 1.00 & $1.00^{\mathrm{a}}$ \\
\hline Supplemented & -- & $0.65^{b}$ & 1.13 & 1.07 & 1.19 & $0.71^{\mathrm{b}}$ \\
\hline \multicolumn{7}{|l|}{ Interactions } \\
\hline Neg/Not Supp & -- & 1.00 & 1.00 & 1.00 & 1.00 & 1.00 \\
\hline Dry/Not Supp & -- & 1.47 & 1.00 & 1.19 & 1.47 & 0.97 \\
\hline P1/Not Supp & -- & 0.86 & 1.60 & 1.58 & 1.04 & 1.02 \\
\hline P2/Not Supp & -- & 0.80 & 1.40 & 1.45 & 1.04 & 1.57 \\
\hline Neg/Supp & -- & 0.76 & 1.44 & 1.71 & 1.15 & 0.72 \\
\hline Dry/Supp & -- & 0.72 & 1.35 & 1.25 & 1.23 & 0.91 \\
\hline P1/Supp & -- & 0.60 & 1.66 & 1.36 & 1.60 & 0.73 \\
\hline P2/Supp & -- & 0.54 & 1.12 & 1.23 & 1.40 & 0.83 \\
\hline \multicolumn{7}{|c|}{ Statistical Effects (P-Value) } \\
\hline In Ovo Treatment & 0.40 & 0.05 & 0.11 & 0.56 & 0.53 & 0.44 \\
\hline Dietary Treatment & -- & 0.001 & 0.26 & 0.48 & 0.15 & 0.02 \\
\hline In Ovo * Diet & -- & 0.62 & 0.20 & 0.07 & 0.31 & 0.55 \\
\hline
\end{tabular}

Table 8: Effect of in ovo and dietary probiotic supplementation on ileal $I L-4$ gene expression (fold change). Different letters within a column indicate significant difference among treatment groups. ${ }^{1} \mathrm{Neg}=$ negative control; ${ }^{2}$ Dry $=$ dry punch; ${ }^{3} \mathrm{P} 1=1 \times 10^{6}$ probiotic bacteria; ${ }^{4} \mathrm{P} 2=1 \times 10^{7}$ probiotic bacteria; ${ }^{5} \mathrm{Not} \quad$ supp=not supplemented; ${ }^{6}$ Supp=supplemented.

Mucin is made up of glycoproteins and serves a protective function by binding to pathogens, thus preventing their adhesion to the intestinal surface. Trefoil factor- 2 is a stable secretory protein expressed in gastrointestinal mucosa responsible for protecting the mucosa from insults, stabilizing the mucus layer and promoting the healing of the epithelium [35]. While no differences were noted for TFF-2 expression, 
Muc-2 levels were increased due to in ovo treatment and dietary supplementation. Previous studies have shown that PrimaLac is able to modulate the processes of mucin synthesis by altering the intestinal bacterial populations [36]. PrimaLac also increased the goblet cell number and mucus secretion in the small intestine of turkeys, which may protect intestinal epithelia from adverse factors including pathogens [37]. The upregulation of $\mathrm{Muc}-2$ also suggests the favoring of a Th2 mediated response.

To evaluate effects on the adaptive immune response, we analyzed gene expression of IFN- $\gamma, L I T A F, I L-4$ and $I L-13 . I F N-\gamma$ is a vital cytokine, secreted mostly by Th1 cells, that plays a central role in regulating the innate and adaptive immune responses, and is responsible for promoting Th1 cell differentiation, suppressing Th2 cell activity, and enhancing innate immune cell activation and function [38]. Expression of $I F N-\gamma$ was differentially downregulated due to in ovo and dietary adminsitration. Expression of LITAF is principally in the spleen of chickens, as well as in intestinal intraepithelial lymphocytes. The LITAF protein is a transcription factor that mediates the expression of members of the tumor necrosis factor ligand superfamily [39]. On d20, expression of LITAF was reduced due to both probiotic administration methods; when coupled with the decrease in $I F N-\gamma$ levels, it further supports the thought that probiotics may promote an anti-inflammatory environment, suppress Th1 activity, and promote a Th2 mediated response. Interleukin-4, a representative of Th2 cytokines, plays a fundamental role in the stimulation of B lymphocytes, $\mathrm{T}$ lymphocyte proliferation, and the differentiation of CD4+ T cells into Th2 cells [40]. The functions of $I L-13$, also characterized as a Th2 cytokine, overlap considerably with those of $I L-4$. Both $I L-4$ and IL-13 function by inhibiting the production of pro-inflammatory modulators. Dietary-administered probiotic, but not in ovo administration, resulted in decreased $I L-4$ expression while no differences were observed in $I L-13$ expression levels.

Other than $M u c-2$, the general trend appears to be a downregulation of host immune-related genes. The decreased transcription of these genes in the probiotic-treated groups may be a response to the inhibitory effects of probiotic bacteria on pathogen colonization. A reduction in intestinal colonization by pathogenic bacteria may have eliminated the need for the induction of these genes. Several studies have demonstrated the ability of probiotics to modulate the levels of several cytokines; however, discrepancies have been noted due to differences in the bacterial strains, combinations of probiotic strains, and presence or absence of a challenge [15-17,22]. Further supporting our findings, many reports have noted decreases in immune-related factors. Akbari et al. reported a downregulation in the expression of antimicrobial peptides in the cecal tonsils of broilers due to probiotic supplementation during a Salmonella infection, attributing the outcome to a reduced Salmonella load in the intestine [41]. Mountzouris et al. found that avilamycin and probiotic treatment result in reduced levels of plasma $\operatorname{IgA}$ and $\operatorname{IgG}$ and intestinal $\operatorname{IgA}$ against Salmonella enteritidis when compared to the challenged control and that those levels were similar to the non-challenged controls [42]. Dalloul et al. observed similar results when they evaluated antibody secretion during a coccidiosis infection between control and probiotic fed birds [43]. When evaluating the effects of probiotic treatment on gene expression in the cecal tonsils of chicks challenged Salmonella, Haghighi et al. found that IL-12 and IFN- $\gamma$ levels were suppressed by probiotic treatment, which correlated with reduced intestinal Salmonella colonization [44]. The immunosuppressive effects seen in these studies could be a result of the reduced colonization capacity of pathogenic bacteria, enhanced clearance, and accelerated recovery caused by the probiotic treatments.

Based on the results presented in this study, the effect of in ovo administration of probiotics on the immune response appears to be similar to that of dietary probiotic supplementation, reinforcing its potential usage to promote early colonization of beneficial bacteria to stimulate intestinal and immune system development. Immunomodulation by in ovo supplementation of probiotics in poultry, and early establishment of beneficial microbiota, may lead to increased overall health and well-being, while decreasing the need for prophylactic antibiotic use due to reduced infection rates. To conclude, these data demonstrate that in ovo supplementation of the commercial probiotic product PrimaLac does not influence hatchability and can alter the expression of several immune-related genes within the ileum. The mode by which the probiotic bacteria may impact the immune system is multi-faceted with effects on both innate and adaptive immunity. Excluding few exceptions, these results support our previous findings in terms of enhancing performance and general downregulation of immune-related genes [22]. This study further elucidates the immunoregulatory effect of probiotics on intestinal immunity in poultry, which may be more pronounced under more challenging conditions [26] as may be encountered in field settings. Moreover, it provides justification for further research to investigate the beneficial effects of probiotics in poultry and the use of in ovo technology as a means of promoting early establishment of beneficial bacteria, development of the local immune system, gut health, and animal well-being.

\section{Acknowledgement}

The authors' work was supported in part by the John Lee Pratt Endowment, Star-Labs Inc., and USDA-NIFA Hatch funds to the Virginia Agricultural Experiment Station.

\section{References}

1. Farnell MB, Donoghue AM, de Los Santos FS, Blore PJ, Hargis BM, et al. (2006) Upregulation of oxidative burst and degranulation in chicken heterophils stimulated with probiotic bacteria. Poult Sci 85: 1900-1906.

2. Patterson JA, Burkholder KM (2003) Application of prebiotics and probiotics in poultry production. Poult Sci 82: 627-631.

3. Kogut MH, Swaggerty CL (2012) Effects of prebiotics and probiotics on the host immune response in Direct-Fed microbials and prebiotics for animals: science and mechanisms of action. Callaway TR, Ricke SC edn Springer, Berlin, Germany.

4. Cox CM, Dalloul RA (2015) Immunomodulatory role of probiotics in poultry and potential in ovo application. Benef Microbes 6: 45-52.

5. Gaggìa F, Mattarelli P, Biavati B (2010) Probiotics and prebiotics in animal feeding for safe food production. Int J Food Microbiol 141: S15S28.

6. Ritzi MM, Abdelrahman W, van-Heerden K, Mohnl M, Barrett NW, et al. (2016) Combination of probiotics and coccidiosis vaccine enhances protection against an Eimeria challenge. Vet Res 47: 111.

7. Beal RK, Powers C, Davison TF, Smith AL (2006) Immunological development of the avian gut. CABI, Wallingford, UK, Cambridge, MA.

8. Smith AL, Powers C, Beal RK (2014) The avian enteric immune system in health and disease. Pages 227-250 in Avian Immunology. Schat KA, Kaspers B, Kaiser P edn. Elsevier Ltd., London, UK.

9. Dibner JJ, Richards JD, Knight CD (2008) Microbial imprinting in gut development and health. J Appl Poult Res 17: 174-188. 
10. Kabir SML, Rahman MM, Rahman MB, Rahman MM, Ahmed SU (2004) The dynamics of probiotics on growth performance and immune response in broilers. Int J Poult Sci 3: 361-364.

11. Nava GM, Bielke LR, Callaway TR, Castañeda MP (2005) Probiotic alternatives to reduce gastrointestinal infections: the poultry experience. Anim. Health Res Rev 6: 105-118.

12. Getachew $\mathrm{T}$ (2016) A review on the effects of probiotic supplementation in poultry performance and cholesterol levels of egg and meat. J World Poult Res 6: 31-36.

13. Higgins SE, Erf GF, Higgins JP, Henderson SN, Wolfenden AD, et al. (2007) Effect of probiotic treatment in broiler chicks on intestinal macrophage numbers and phagocytosis of Salmonella Enteritidis by abdominal exudate cells. Poult Sci 86: 2315-2321.

14. Stringfellow K, Caldwell D, Lee J, Mohnl M, Beltran R, et al. (2011) Evaluation of probiotic administration on the immune response of coccidiosis vaccinated broilers. Poult Sci 90: 1652-1658.

15. Dalloul RA, Lillehoj HS, Tamim NM, Shellem TA, Doerr JA (2005) Induction of local protective immunity to Eimeria acervulina by a Lactobacillus-based probiotic. Comp Immunol Microbiol Infect Dis 28: 351-361.

16. Brisbin JT, Gong J, Parvizi P, Sharif S (2010) Effects of Lactobacilli on cytokine expression by chicken spleen and cecal tonsil cells. Clin Vaccine Immunol 17: 1337-1343.

17. Lee KW, Lee SH, Lillehoj HS, Li GX, Jang SI, et al. (2010) Effects of directfed microbials on growth performance, gut morphometry, and immune characteristics in broiler chickens. Poult Sci 89: 203-216.

18. Dalloul RA, Lillehoj HS (2005) Recent advances in immunomodulation and vaccination strategies against coccidiosis. Avian Dis 49: 1-8.

19. Knap I, Lund B, Kehlet AB, Hofacre C, Mathis G (2010) Bacillus licheniformis prevents necrotic enteritis in broiler chickens. Avian Dis 54: 931-935.

20. Ritzi MM, Abdelrahman W, Mohnl M, Dalloul RA (2014) Effects of probiotics and application methods on performance and response of broiler chickens to an Eimeria challenge. Poult Sci 93: 2772-2778.

21. Pedroso AA, Menten JFM, Lambais MR (2005) The structure of bacterial community in the intestines of newly hatched chicks. J Appl Poult Res 14: 232-237.

22. Pender CM, Kim S, Potter TD, Ritzi MM, Young M, et al. (2017). In ovo supplementation of probiotics and its effects on performance and immune-related gene expression in broiler chicks. Poult Sci 96: 1052-1062.

23. Silva IGO, Vellano IHB, Moraes AC, Lee IM, Alvarenga B, et al. (2017) Evaluation of a probiotic and a competitive exclusion product inoculated in ovo on broiler chickens challenged with Salmonella Heidelberg. Braz J Poultry Sci 19: 19-26.

24. Cox NA, Bailey JS, Blankenship LC, Gildersleeve RP (1992) Research note: in ovo administration of a competitive exclusion culture treatment to broiler embryos. Poult Sci 71: 1781-1784.

25. Meijerhof R, Hulet RM (1997) In ovo injection of competitive exclusion culture in broiler hatching eggs. J Appl Poult Res 6: 260-266.

26. Pender CM, Kim S, Potter TD, Ritzi MM, Young M, et al. (2016) Effects of in ovo supplementation of probiotics on performance and immunocompetence of broiler chicks to an Eimeria challenge. Benef Microbes 7: 699-705.

27. Edens FW, Parkhurst CR, Casas IA, Dobrogosz WJ (1997) Principles of ex ovo competitive exclusion and in ovo administration of Lactobacillus reuteri Poult Sci 76: 179-196.
28. Livak KJ, Schmittgen TD (2001) Analysis of relative gene expression data using real-time quantitative PCR and the 2(-Delta Delta C(T)) Method. Methods 25: 402-408.

29. Ahmadi F (2011) The effect of Saccharomyces cervisiae (Thepax) on performance, blood parameters and relative weight of lymphoid organs of broiler chicks. Global Vet 6: 471-475.

30. Sadeghi AA, Shawrang P, Shakorzadeh S (2015) Immune response of Salmonella challenged broiler chickens fed diets containing Gallipro ${ }^{\oplus}$, a Bacillus subtilis probiotic. Probiotics Antimicrob Proteins 7: 24-30.

31. Al-Barwary LT, Shahin MG, Tayeb IT (2012) Effect of probiotic supplementation on broiler performance. Int J App Poult Res 1: 27-29.

32. Naseem S, Rahman SU, Shafee M, Sheikh AA, Khan A (2012) Immunomodulatory and growth-promoting effect of a probiotic supplemented in the feed of broiler chicks vaccinated against infectious bursal disease. Rev Bras Cienc Avic 14: 109-113.

33. Tizard IR (2009) Veterinary immunology: an introduction. 8th edn Saunders Elsevier, St. Louis, MO.

34. Beum PV, Basma H, Bastola DR, Cheng PW (2005) Mucin biosynthesis: upregulation of core 2 beta 1,6 $\mathrm{N}$-acetylglucosaminyltransferase by retinoic acid and Th2 cytokines in a human airway epithelial cell line. Am J Physiol Lung Cell Mol Physiol 288: L116-L124.

35. Jiang Z, Lossie AC, Applegate TJ (2011) Evolution of trefoil factor(s): genetic and spatio-temporal expression of trefoil factor 2 in the chicken (Gallus gallus domesticus). PLoS One 6: e22691.

36. Smirnov A, Perez R, Amit-Romach E, Sklan D, Uni Z (2005) Mucin dynamics and microbial populations in chicken small intestine are changed by dietary probiotic and antibiotic growth promoter supplementation. J Nutr 135: 187-192.

37. Rahimi S, Grimes JL, Fletcher O, Oviedo E, Sheldon BW (2009). Effect of a direct-fed microbial (Primalac) on structure and ultrastructure of small intestine in turkey poults. Poult Sci 88: 491-503.

38. Kaiser P, Staheli P (2014) Avian cytokines and chemokines. Pages 189-204 in Avian Immunology. Elsevier, London, UK.

39. Hong YH, Lillehoj HS, Lee SH, Park D, Lillehoj EP (2006) Molecular cloning and characterization of chicken lipopolysaccharide-induced TNF-alpha factor (LITAF). Dev Comp Immunol 30: 919-929.

40. Fietta P, Delsante G (2009) The effector T helper cell triade. Riv Biol 102: 61-74.

41. Akbari MR, Haghighi HR, Chambers JR, Brisbin J, Read LR, et al. (2008) Expression of antimicrobial peptides in cecal tonsils of chickens treated with probiotics and infected with Salmonella enterica serovar Typhimurium. Clin Vaccine Immunol 15: 1689-1693.

42. Mountzouris KC, Balaskas C, Xanthakos I, Tzivinikou A, Fegeros K (2009) Effects of a multi-species probiotic on biomarkers of competitive exclusion efficacy in broilers challenged with Salmonella Enteritidis. Br Poult Sci 50: 467-478.

43. Dalloul RA, Lillehoj HS, Shellem TA, Doerr JA (2003) Enhanced mucosal immunity against Eimeria acervulina in broilers fed a Lactobacillus-based probiotic. Poult Sci 82: 62-66.

44. Haghighi HR, Abdul-Careem MF, Dara RA, Chambers JR, Sharif S (2008) Cytokine gene expression in chicken cecal tonsils following treatment with probiotics and Salmonella infection. Vet Microbiol 126: 225-233. 